\title{
ポーラログラフイーへのラプラス変換の応用（Ｉ）㝍説*
}

神原富 此***

ボーラログラフ的電極文応諭の特筫は, 雪解 現象在非定常的変化と考元て执散の現像を数等

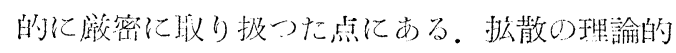
な彼り扱いは物理数学的な困難を件うものであ るが, Kouteckyと Brdicka ${ }^{1)}$ によて理論 ポーラログラフィーに始めて導入されたラプラ

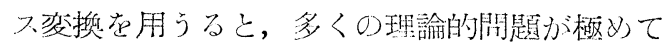

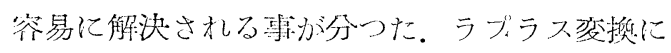
ついては多くの成書(6-17) が発行されて庫るが，

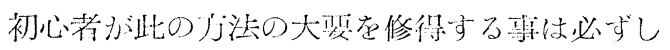

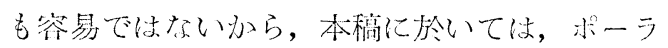

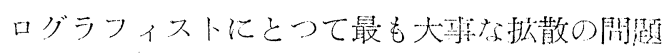
についての計算の詳細を述心゙よう。

\section{Fick の法則と誤差函数}

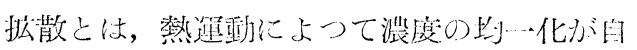
発的に起る現象であり， Fick の泛则と叱げれ

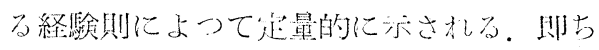

$$
\text { flux }=\frac{d n}{q \cdot d t}=-D_{\partial x}^{\partial C}
$$

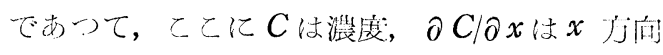

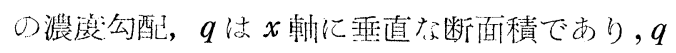
を貫いて $d i$ 時間中に移動する物筫の量 $d n$ は

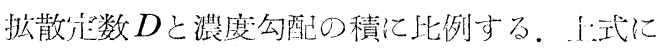
亦す flux (流束) と言う量は，紧位面積を貴い て监位時開に移動する物質の量で，大きさと方 向と在有するバクトル量である。(1) 式は Fick の第 1 則と呼ばれる。xなる位置での濃度勾配 と flux が(1)式で与えられるとすれば， $x+d x$ なる位置に於ける抾散の速度は，Taylor 展開 によつて

* Application of Laplace-Transformation to Polarography. I. Introduction.

T. Kambara, Department of Agricultural Chemistry, Kyoto University

$$
\begin{gathered}
(d n)_{x+a x} \\
q \cdot d t
\end{gathered}=-D\left(\frac{\partial C}{\partial x}+\frac{\partial^{2} C}{\partial x^{2}} \cdot d x\right)
$$

となる。1:002 武尼边々相減与゙ると。

$$
\frac{(d n)_{x}-(d n)_{x+d x}}{q \cdot d x \cdot d t}=D \frac{\partial^{2} C}{\partial x_{2}}
$$

となるが，ての式の左过は， $q \cdot d x$ と言う微小 休積帆入つて来る物質の量と, ここから州て 行く量とり差在倈積 $q \cdot d x$ で制り，更に $d i て ゙$ 制つたものに等しい。従つて, 1 式の左边统,

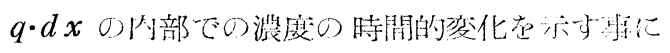
宗り，かくして Fick の第 2 则：

$$
\frac{\partial C}{\partial t}=D \frac{\partial^{2} C}{\partial x^{2}}
$$

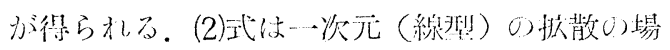
合に成的する。

さて，トに導いた微分引程式(2)心, 静止平面

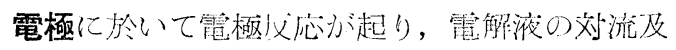
びイオンの泳動小無視され得る場合に成向す

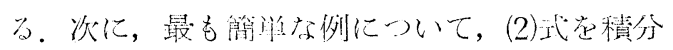

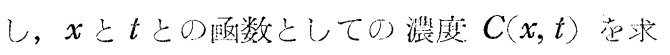
ע) 5 .

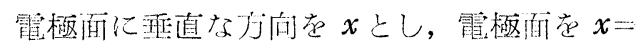

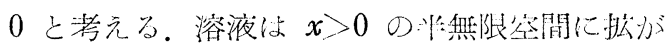

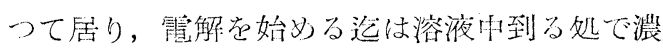

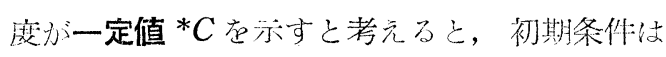
炏式によつて与光られる。

$$
t=0, \quad 0 \leq x \leq \infty, \quad C={ }^{*} C
$$

或は文, $C(x, 0)={ }^{*} C$ と珰いてもよい. 此の祭 $t$ は篦解閉始後の時間を示すものとする。箐解 開始後, 問題の静止平面電極には一定電玉が加 えられ，その結果，電極表面に於ける復極剬の

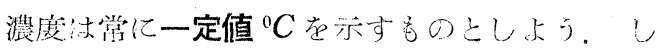
加石時, 境界条件は 
$t>0, \quad x=0, \quad C={ }^{\circ} \mathrm{C}$

(4)

となり, 或は义, $C(0, t)={ }^{\circ} C$ と書いてもよい. 次に(3) 及び(4)の2 条件を用いて，(2)式を積分 し上5。

新しい变数として,

$$
y=\frac{x}{2 \sqrt{D t}}
$$

学導入し，隶数 $C$ は $y$ みによつて完全に表現 され得るものと做定する。そうすると，

$$
\frac{\partial C}{\partial t}=\frac{d C}{d y} \cdot \frac{\partial y}{\partial t}
$$

の装領で計算すると，(2)式は

$$
-2 y=\frac{d^{2} C / d y^{2}}{d C / d y}
$$

となり，之を積分すると，

$$
\ln \frac{d C}{d y}=-y^{2}+\text { const. }
$$

となる。従つて $A$ と $B$ とを定数として,

$$
\begin{aligned}
& \frac{d C}{d y}=A \cdot e^{-y / 2} \\
& C(y)=A \int_{0}^{y} e^{-u \cdot 2} \cdot d u+B
\end{aligned}
$$

お澊かれる。(3)及び(4)心条件を酹き換えると，

$$
\begin{array}{ll}
y=\infty, & C={ }^{*} C \\
y=0, & C={ }^{0} C
\end{array}
$$

となる。従つて

$$
A=\frac{{ }^{*} C-{ }^{\circ} C}{\int_{0}^{\infty} e^{-u 2} \cdot d u}=\frac{2}{\sqrt{\pi}}\left({ }^{*} C-{ }^{0} C\right) ; B={ }^{0} C
$$

扂得る. Gauss の誤差函数 (error function):

$$
\operatorname{erf} y \equiv \frac{2}{\sqrt{\pi}} \int_{0}^{y} e^{-u 2} \cdot d u
$$

花用うると，求方る解は

$$
C={ }^{\circ} C+\left({ }^{*} C-{ }^{\circ} C\right) \cdot \operatorname{erf}\left(\frac{x}{2 \sqrt{D t}}\right)
$$

となる。或は又,

$$
\operatorname{erfc} y \equiv 1-\operatorname{erf} y=\frac{2}{\sqrt{\pi}} \int_{y}^{\infty} e^{-u z} \cdot d u
$$

に上つて示される余誤差函数 (Complementary error function) 应用うると，

$$
C={ }^{*} C-\left({ }^{*} C-{ }^{0} C\right) \cdot \operatorname{erfc}\left(\frac{x}{2 \sqrt{D t}}\right)
$$

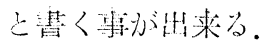

(8)式水ら,

$$
\frac{\partial C}{\partial x}=\frac{{ }^{*} C-{ }^{0} C}{\sqrt{\pi D t}} \cdot \exp \left(\frac{-x^{2}}{4 D t}\right)
$$

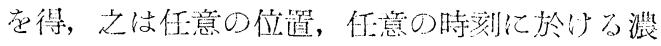

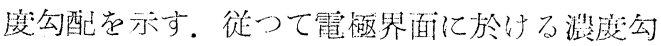
配は

$$
\left(\frac{\partial C}{\partial x}\right)_{x=0}=\frac{{ }^{*} C-{ }^{\circ} C}{\sqrt{\pi D t}}
$$

となる。

\section{附記}

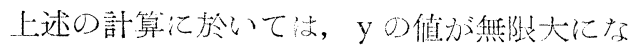

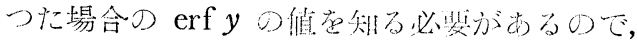
その求方方簡鞋に述心゙る。

$$
I=\int_{0}^{\infty} e^{-y 2} \cdot d y=\int_{0}^{\infty} e^{-x 2} \cdot d x
$$

と韾けば

$$
I^{2}=\int_{0}^{\infty} \int_{0}^{\infty} e^{-\left(x^{2}+y^{2}\right)} \cdot d x \cdot d y
$$

である。この 2 重積分は, 第 1 洞に於いて $e^{-(x 2+y 2)}$ なる被積分呕数仙 $d x \cdot d y$ を掤けたる のの值を， $x$ と $y$ とのすべての正の值，卯ち $x, y$-平面の第 1 像限の全部に亘つて積算した ものを意味する。さて, 動径 $\gamma$ と偏角 0 とを新 しい変数として導入正ると,

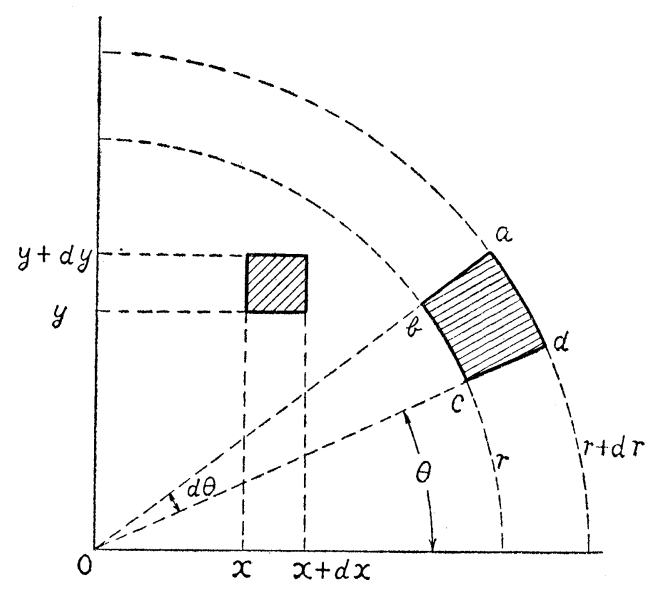

Fig. 1

$$
r^{2}=x^{2}+y^{2}
$$

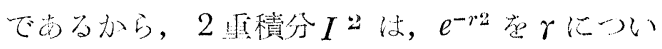

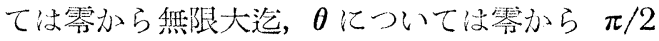




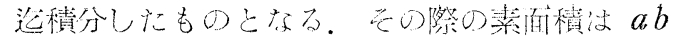
$c d$ によって亦さ机，明ら小に

$$
\begin{aligned}
& a b=c d=d r \\
& a d=b c=r \cdot d \theta
\end{aligned}
$$

である。徤つて

$$
\begin{aligned}
I^{2} & =\int_{0}^{\pi / 2} d \theta \int_{0}^{\infty} e^{-r 2} \cdot r \cdot d r= \\
& =\int_{0}^{\pi / 2}\left[\frac{-1}{2} \cdot e^{-r 2}\right]_{0}^{\infty} \cdot d \theta=\left[\frac{\theta}{2}\right]_{0}^{\pi / 2}=\frac{\pi}{4}
\end{aligned}
$$

こなる。しかるに $I>0$ であるから，

$$
I=\int_{0}^{\infty} e^{-y 2} \cdot d y=\frac{\sqrt{ } \pi}{2}
$$

となる。

\section{II. ラプラス変換の定義と変換表}

Heaviside の「演算子法」とは，微分门程式 中の微分符写 $d / d t$ 在涪男的に $p$ で置き撸えて 微分门程式老解〉了法である。此の广法法後に

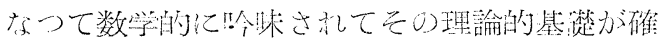
立され，ラプラス変換と徆ばれる心用数等の... 分野を形成するに至つた。

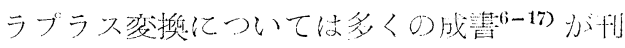

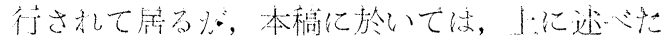

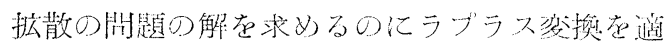
用する例について述心゙ホボーラログラフィスト にとつて最も重要な問題に即して其体的に記述 しょう.

ラプラス変換は次式によつて起篓せられる。

$$
L F(t)=\int_{0}^{\infty} F(t) \cdot e^{-s t} \cdot d t=f(s)
$$

即ち, $t$ の函数 $F(t)$ に $e^{-s t}$ を乘じ, $t$ 亿ついて 零加ら無限大迄積分与ると, $s$ の函数 $f(s)$ 范 得る。濃度 $C$ が $x$ と $t$ との函数の場合には, 引 ブラス変換忖次式によつて定義せられる。

$$
L C(x, t)=\int_{0}^{\infty} C(x, t) \cdot e^{-s t} \cdot d t=u(x, s)
$$

\begin{tabular}{|c|c|c|}
\hline 交献 & $F(t)$ & $f(s)[$ 父は $\phi(p)]$ \\
\hline $\begin{array}{l}6,7 \\
16, \quad 17 \\
8,9, \quad 10\end{array}$ & $\begin{array}{l}\text { 対像崡数 (ofbject function) } \\
\text { 原始崡数 (original function) } \\
\text { 上位崡数 (Oberfunktion) }\end{array}$ & $\begin{array}{l}\text { 結果函数 (result function) } \\
\text { 像 圂 数 (image function) } \\
\text { 下位崡数 (Unterfunktion) }\end{array}$ \\
\hline
\end{tabular}

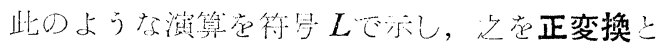
呼ぶ. $F^{\prime}(t)$ と $f(s)$ とは一般化一対一の対応觉 なす。即ち，種々の $t$ の函数にはをれでれ刘沈

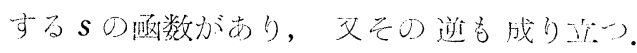

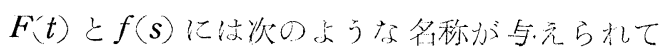
居方。
次に, $f(s)$ 亿刘灾する $F(t)$ 苍求义る演算を逆 変換之呼び，記晃的に㳊

$$
L^{-1} f(s)=F(t)
$$

之菖: $<$,

(13)式に亦す要換と影り，

$$
L F(t)=p \int_{0}^{\infty} F(t) \cdot e^{-p t} \cdot d t=\phi(p)
$$

によつで过䉝世られる变換在用うる等者も多

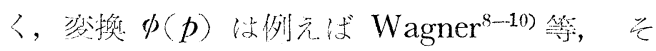
の他の篦狂工学者によつて採用されて居る。(13)

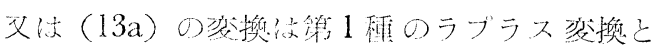
阿代れ，之に刘して（13b）式によつて与。ら れる変換は第 2 種のラプラス炙掺と呼ばれる。
耐種の变換の䦎には

$$
\phi(p)=p \cdot f(p)
$$

の関係が成立し，簡策な形式トの差異があるだ けである。本稿に於いては(13)式による第 1 㮔の ラブラス変換に隼じて記述する。

次住変換の計算例を述べる。

（1） $k$ 起任瑟の定数とすると

$$
L k=\int_{0}^{\infty} k \cdot e^{-s t} \cdot d t=\left[\frac{-k}{s} \cdot e^{-s t}\right]_{0}^{\infty}=\frac{k}{s}
$$

（2） $t$ に 劣換を施す。部分積分法に上り

$$
\begin{aligned}
L t= & \int_{0}^{\infty} t \cdot e^{-s t} \cdot d t=\left[t \frac{-1}{s} \cdot e^{-s t}\right]_{0}^{\infty} \\
& +\int_{0}^{\infty} \frac{1}{s} \cdot e^{-s t} \cdot d t=\frac{1}{s^{2}}
\end{aligned}
$$


(3) $1 / \sqrt{\pi t}$ 亿 $L$ 変換を施与.

$$
L \frac{1}{\sqrt{\pi t}}=\int_{0}^{\infty} \frac{1}{\sqrt{\pi t}} e^{-s t} \cdot d t
$$

に於いて,

$$
\sqrt{s t}=y ; d t=\frac{2 y}{s} \cdot d y
$$

と置くと,

$$
L \frac{1}{\sqrt{\pi t}}=\frac{2}{\sqrt{\pi s}} \int_{0}^{\infty} e^{-y z} \cdot d y=\frac{1}{\sqrt{s}}
$$

\section{在得る。}

（4）余䛊差呕数の変換. 部分積分法により

$$
\begin{aligned}
L \operatorname{erfc} & \left(\frac{k}{2 \sqrt{t}}\right) \\
& =\left[\frac{-1}{s} \cdot e^{-s t} \cdot \operatorname{erfc}\left(\frac{k}{2 \sqrt{t}}\right)\right]_{0}^{\infty} \\
& +\int_{0}^{\infty} \frac{1}{s} \cdot e^{-s t} \frac{2}{\sqrt{\pi}} \cdot \\
& e^{-n^{2} / 4 t} \cdot \frac{k}{4 t \sqrt{t}} \cdot d t
\end{aligned}
$$

となるが，上式り右辺の第 1 項は零となる。

$$
\frac{k}{2 \sqrt{t}}=y ; \frac{-k}{4 t \sqrt{t}} \cdot d t=d y
$$

と犆くと

$$
\begin{gathered}
L \operatorname{erfc}\left(\frac{k}{2 \sqrt{t}}\right)=\int_{0}^{\infty} \frac{2}{s \sqrt{\pi}} . \\
\quad \exp \left(-\frac{k^{2} s}{4 y^{2}}-y^{2}\right) \cdot d y
\end{gathered}
$$

となる。更に積分変数を次のように変える。

$$
\sqrt{s t}=\eta ; s i=\eta^{2} ; \frac{1}{2} \sqrt{\frac{s}{t}} \cdot d t=d \eta
$$

しかる時 (i) 式より

$$
\begin{aligned}
L \operatorname{erfc} & \left(\frac{k}{2 \sqrt{t}}\right) \\
& =\int_{0}^{\infty} \exp \left(-\eta^{2}-\frac{k^{2} s}{4 \eta^{2}}\right) \cdot \frac{k}{\sqrt{s \pi}} \cdot \frac{d \eta}{\eta^{2}}
\end{aligned}
$$

定得る。さて，

$$
\eta^{2}+\frac{k^{2} s}{4 \eta^{2}}=\left(\eta-\frac{k \sqrt{s}}{2 \eta}\right)^{2}+k \sqrt{ } s
$$

の関係を用いて

$$
\eta-\frac{k \sqrt{s}}{2 \eta}=m ;\left(1+\frac{k \sqrt{ } s}{2 \eta}\right) d \eta=d m
$$

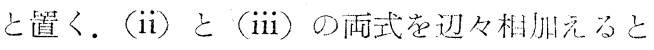

$$
\begin{aligned}
2 L \operatorname{erfc}\left(\frac{k}{2 \sqrt{i}}\right)=\frac{2}{\sqrt{\pi}} \int_{0}^{\infty} e^{-k_{\sqrt{ } s}} . \\
e^{-m^{2}}\left(\frac{1}{s}+\frac{k}{2 \eta^{2} \sqrt{s}}\right) d \eta \\
\quad=\frac{e^{-k_{\sqrt{s}}}}{s} \cdot \frac{2}{\sqrt{\pi}} \int_{-\infty}^{+\infty} e^{-m^{2}} \cdot d m \\
\quad=\frac{e^{-k_{\sqrt{s}}}}{s} \cdot \frac{4}{\sqrt{\pi}} \int_{0}^{\infty} e^{-m^{2}} \cdot d m
\end{aligned}
$$

となるが，此の際，(ii）式の右辺の砸分然数の

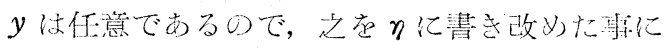
留意也ら机たい。上式に(12)式在代入すると

$$
L \operatorname{erfc}\left(\frac{k}{2 \sqrt{t}}\right)=\frac{e^{-k \sqrt{s}}}{s}
$$

が得られるが，一般に扰散の開题に於いて、紧 な愦善呕数を含毛諸呕数の变換の計算は比較的 面倒である。

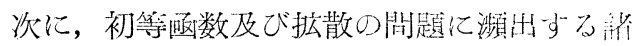
函数の変換の数例在表示与る(第 1 衣).

第 1 表 ラプラス変換表

\begin{tabular}{l|c|cc}
\hline No. & $F(t)$ & & $f(s)$ \\
\hline 1 & $k$ (定数) & & $k / s$ \\
2 & $t$ & & $1 / s^{2}$ \\
3 & $\frac{t^{n-1}}{(n-1) !}$ & $(n=1,2, \cdots \cdots)$ & $\frac{1}{s^{n}}$ \\
4 & $\frac{1}{\sqrt{\pi t}}$ & & $\frac{1}{\sqrt{s}}$ \\
5 & $2 \sqrt{\frac{t}{\pi}}$ & & $s^{-3 / 2}$
\end{tabular}




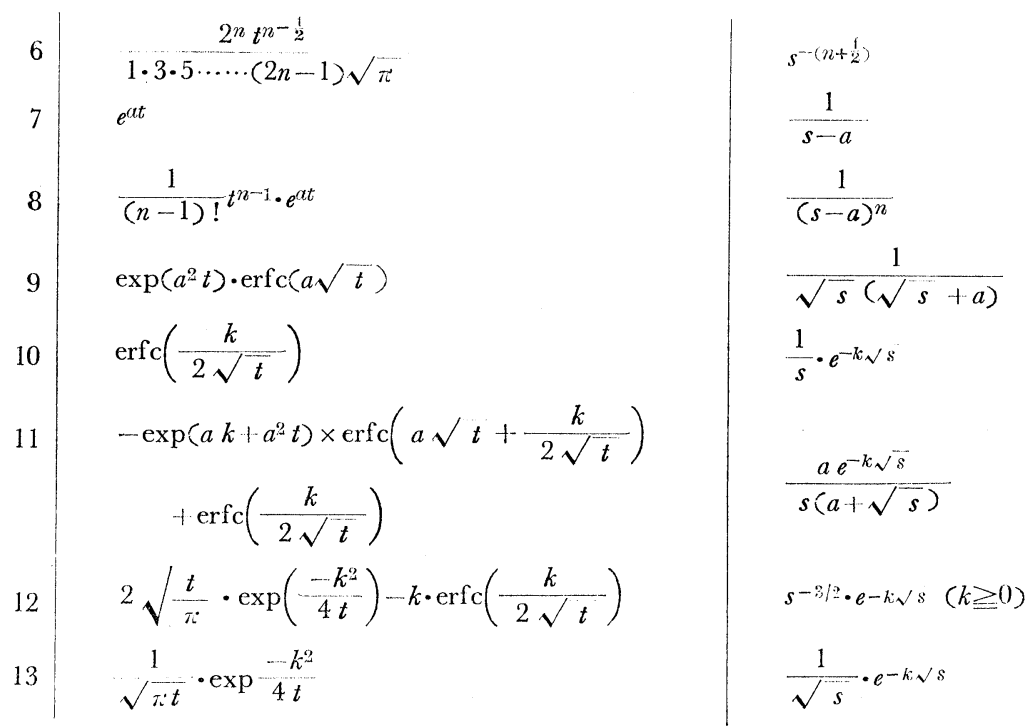

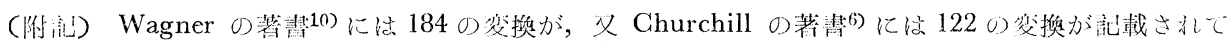
居る。後者は Hodgman の Handbook of Chem. and Physics (1956) 37th Ed. 飞老此

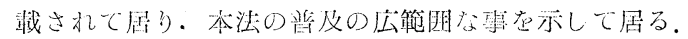

\section{III. ラプラス変換を用いての拡散の 微分方程式の解法}

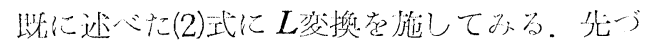
(2)式の左辺に一いては，部分積分法により

$$
\begin{aligned}
L^{\frac{\partial C}{\partial t}} & =\int_{0}^{\infty} \frac{\partial C}{\partial t} \cdot e^{-s t} \cdot d t \\
& =\left[C \cdot e^{-s t}\right]_{0}^{\infty}-\int_{0}^{\infty} C \cdot(-s) \cdot e^{-s t} \cdot d t \\
& =-C(x, 0)+s \cdot L C \\
& =s\left\{u(x, s)-\frac{{ }^{*} C}{s}\right\}
\end{aligned}
$$

と被り，此の際初期条件(3)式方用いられた。(2) 武の右迊について蛙,

$$
L\left[D \frac{\partial^{2} C}{\partial x^{2}}\right]=D \frac{d^{2}}{d x^{2}}(L C)=D \frac{d^{2} u(x, s)}{d x^{2}}
$$

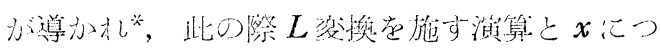

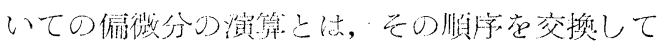

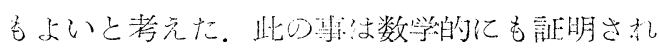
得る刃゙，锌細没省略する。

以1:0計算示ら

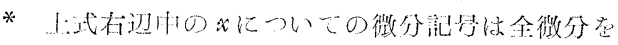

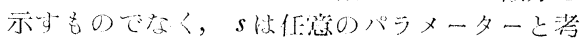
えるべきである。 $D \cdot \partial^{2} u(x, s) / \partial x^{2}$ 己澘かれ て居る文献も多い1-2)。

$$
\begin{gathered}
\stackrel{s}{D}\left\{u^{\prime}(x, s)-\frac{{ }^{*} C}{s}\right\}=\frac{d^{2} u^{\prime}(x, s)}{d x^{2}} \\
=\frac{d^{2}}{d x^{2}}\left\{u(x, s)-\frac{C^{*}}{s}\right\}
\end{gathered}
$$

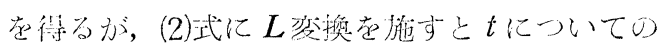

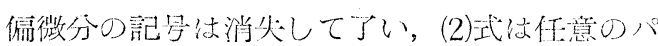
ラメーター $s$ 死含充学微分广程式に還无された 过非明する。

さて，(15)式を穦分すると

$$
\begin{gathered}
u(x, s)=\frac{{ }^{*} C}{s}+A \cdot \exp \left(\sqrt{ } \frac{s}{D} x\right) \\
+B \cdot \exp \left(-\sqrt{\frac{s}{D}} x\right)
\end{gathered}
$$

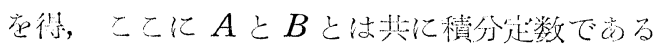

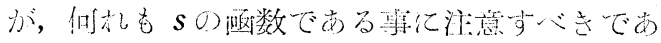
る。此の䅡分起数は次に示すように境界条件に よつて決这せられ\%。

少一゙

$$
x \rightarrow \infty, \quad C={ }^{*} C
$$

であるから

$$
A=0
$$

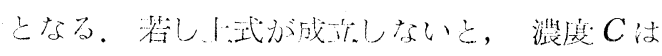
$x \rightarrow \infty$ で無限大になつて不都合で尚る。文，(4) 


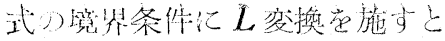

$$
u(0, s)=L C(0, t)=\frac{{ }^{\circ} \mathrm{C}}{s}
$$

となり，他方 (16)一(18)式小らは

$$
u(0, s)=\frac{{ }^{*} C}{s}+B
$$

を得る。上の 2 式を比較すると $B$ が定紊り

$$
B=-\frac{1}{s}\left({ }^{*} C-{ }^{0} C\right)
$$

となる。従つて

$$
\begin{aligned}
u(x, s) & =\frac{{ }^{*} C}{s} \\
& -\frac{\left({ }^{*} C-{ }^{0} C\right)}{s} \cdot \exp \left(-\sqrt{\frac{s}{D} x}\right)
\end{aligned}
$$

在得る。変換表の公式の No. 1 と No.10 と老 用うると, $u(x, s)$ に対応する $C(x, t)$ が得ら れる。即占

$$
\begin{aligned}
& L^{-1} u(x, s)=C(x, t) \\
&={ }^{*} C-\left({ }^{*} C-{ }^{0} C\right) \cdot \operatorname{erfc} \frac{x}{2 \sqrt{D t}}
\end{aligned}
$$

であつて，先汇導いた(8)式の解がラプラス変換 によつて得られた訳である。

以上の計算例から， $L$ 変換による解法の特長 を次のように述心゙る事が出来る，2変数の偏微 分方程式(2) 亿 $L$ 変換を施与と, 初期条件考考慮 に入れた常微分方程式(15) 肪得られ，t亿ついて の偏微分の記号は消失する。此の常溦分方程式 を積分してその積分定数を境界条件によつて決 定すると，求める雨数 $C(x, t)$ 飞刘応する変換 $u(x, s)$ が得られる。 $u(x, s)$ 亿逆変換施をすと 求》る函数 $C(x, t)$ 少得られる分，此の逆変換 の演算は変換表を可けば得られる。以上の上う に，L变換を用いて微分门程式を解くと変数の 数がーD減少する事になるので計算は大変容易 になり，且つ変換表を用いると機械的に所项の 解が得られる訳であつて，近藤の著書 ${ }^{17}$ 亿於い ては，此の辺の事情が，実数 $m \circlearrowleft a$ 乘の $b$ 乖 根ひ計算を対数表を用いて行うと，表を引く学 苦と簡算な積や商の計算で数值が求まる容易さ そたとえられて記述されて居る。

むて次に， $t$-雨数と $s$-函数とU刘忍沙 $C(x, t) \succeq u(x, s)$ 代小りでなく，きれぞれの

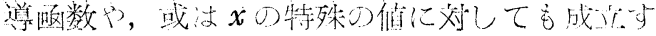

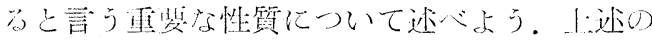
例加

$$
\begin{aligned}
& u(\infty, s)={ }^{*} C / s=L C(\varsigma, t) \\
& u(0, s)={ }^{\circ} C / s=L C(0, t)
\end{aligned}
$$

である事が導かれる。又，恋換表のNo.13 芷 用いると，

$$
\begin{gathered}
L^{-1}\left(\frac{\partial u}{\partial x}\right)=L^{-1}\left[\frac{{ }^{*} C-{ }^{0} C}{\sqrt{D s}} .\right. \\
\left.\quad \exp \left(-\sqrt{\frac{s}{D}} x\right)\right]=\frac{\partial C}{\partial x} \\
\quad=\frac{{ }^{*} C-{ }^{0} C}{\sqrt{\pi D t}} \cdot \exp \left(\frac{-x^{2}}{4 D t}\right)
\end{gathered}
$$

が導かれ，先任導いた (10)式が得られる。同し $<$,

$$
\begin{array}{r}
L^{-1}\left(\frac{\partial u}{\partial x}\right)_{x=0}=L^{-1} \frac{{ }^{*} C-{ }^{\circ} C}{\sqrt{D s}} \\
\quad=\left(\frac{\partial C}{\partial x}\right)_{x=0}=\frac{{ }^{*} C-{ }^{\circ} C}{\sqrt{\pi D t}}
\end{array}
$$

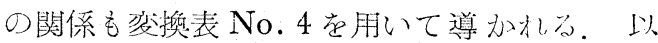
上の例から判明するように，ラプラス変換に上 る解法侮しては， $C(x, s)$ と言う完全小解小゙ たとえ得られない場合でも，( $(\partial C / \partial x)$ 义は $(\partial C / \partial x)_{x=0}$ の如き知らんと欲する量老時閒の 呕数として求め得るのであつて，之はラフ’ラ 変換による解法の極めて大きな実際的特長であ る.

\section{IV. 初步的応用問題}

二三の応用例に大る前に，電極又伈諭化於い て画要な境界条件について述べる。

\section{（a）連続の法則}

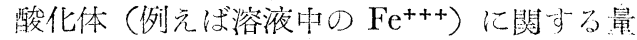
そは添字 O在用い，還元体（例光ば溶液中の $\left.\mathrm{Fe}^{++}\right)$そついて哇添字Rを用いると，両者の搪 散は連立偏微分广程式：

$$
\frac{\partial C_{0}}{\partial t}=D_{0} \frac{\partial^{2} C_{0}}{\partial x^{2}} ; \frac{\partial C_{\mathrm{R}}}{\partial t}=D_{\mathrm{R}} \frac{\partial^{2} C_{\mathrm{R}}}{\partial x^{2}} \quad \text { (22) }
$$

によつて示される。さて，

$$
x \rightarrow \infty, \quad C={ }^{*} C, \quad \partial C / \partial x=0
$$

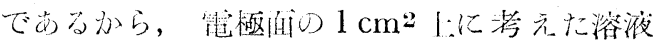




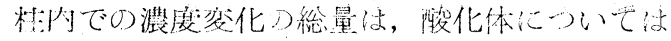

$$
\begin{aligned}
\int_{0}^{\infty} \frac{\partial C_{0}}{\partial t} \cdot d x & =\left[D_{0} \frac{\partial C_{0}}{\partial x}\right]_{0}^{\infty} \\
& =-D_{0}\left(\frac{\partial C_{0}}{\partial x}\right)_{x=0}
\end{aligned}
$$

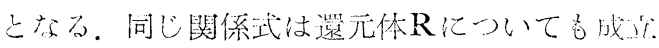
す\%。若しも界面 $x=0$ で酸化体又は遗元体の 蓄積わ潕いとすれい゙，物簧不減の法則により， 消失した酸化体の量は，如何子る時刻飞於いて も，新しく生成した澴元体の量に等しい，徒つ $\tau$,

$$
\begin{aligned}
t>0, & x=0, \quad D_{0} \frac{\partial C_{0}}{\partial x} \\
& =-D_{\mathrm{R}} \frac{\partial C_{\mathrm{R}}}{\partial x}=\frac{i}{n \mathrm{~F} q}
\end{aligned}
$$

で沈方。ここに

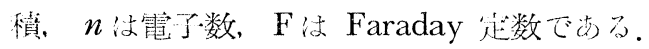
(24)式は Sevcik²)によつて導かれた。

\section{(b) 電極反応速度定数}

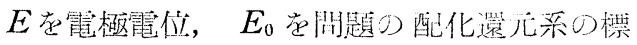

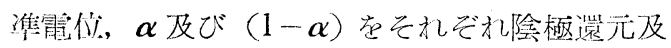
び陽極酸化の移動係数とすると（但し $0<\alpha<$ 1), 虺元と酸化との速应过数 $\vec{k}$ 及び 上つて与去られ\%。

$$
\left.\begin{array}{l}
\vec{k}=k_{s} \cdot \exp \frac{-\alpha n \mathrm{~F}\left(E-E_{0}\right)}{\mathrm{R} T} ; \\
\overleftrightarrow{k}=k_{s} \cdot \exp \frac{(1-\alpha) n \mathrm{~F}\left(E-E_{0}\right)}{\mathrm{R} T}
\end{array}\right\}
$$

ここに $k_{s}$ 洨， $E=E_{0}$ に於ける速速这数である。 $x=0$ 亿於ける雨体つ活量係数な $f_{0}$ 及び $f_{\mathrm{R}}$ と市 ると,

$$
t>0, x=0, \frac{i}{n \mathrm{~F} q}=\vec{k} f_{0} C_{0}-\stackrel{\leftarrow}{k} f_{\mathrm{R}} C_{\mathrm{R}}(26)
$$

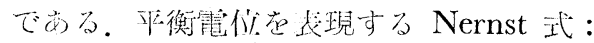

$$
E=E_{0}+\frac{\mathrm{R} T}{n \mathrm{~F}} \ln \frac{f_{0} C_{0}}{f_{\mathrm{R}} C_{\mathrm{R}}}
$$

$$
\text { は(26)式に於いて } i=0 \text { の場合江相当する. }
$$

\section{(c) 可逆電極反応}

多くの理論的・実駼的研究㸚ら判明したよう に， $k_{s}$ が極》て大きい場合には，速度論的な 境貥条件 (26)式の代りに, Nernst 式在境界条件

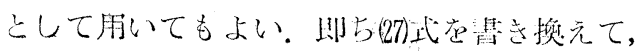

$$
t>0, x=0, \frac{C_{0}}{C_{\mathrm{R}}}=\frac{f_{\mathrm{R}}}{f_{0}} \cdot \exp \frac{n \mathrm{~F}\left(E-E_{0}\right)}{\mathrm{R} T}
$$

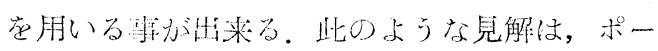
ラログラフ波の最初の理論的考察として知られ る Heyrovsky-Ilkovic 理論に於いて述心゙られ たもので方り，(28)式老睍界条件として採用して も美支觉ない酸化還元采は，与无られた実験条 件下では，速底諭的に可逆と霍われる。此の言

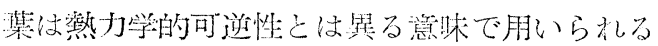
牙留意也られたいる。.

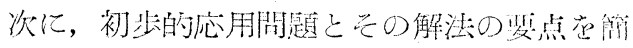
㫛に处心よう。

\section{〔問題 1 〕}

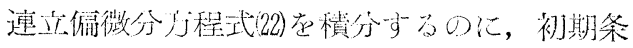

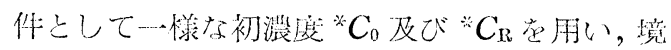
界条件としては連絸の注則 (24) 式及び $E=$ const.

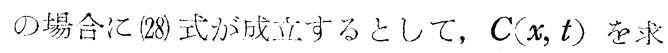

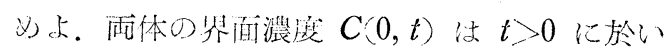

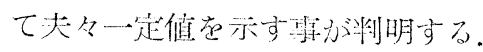

\section{〔問題 2〕}

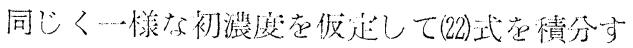

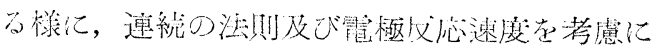

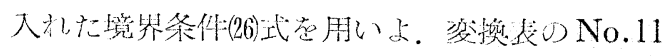

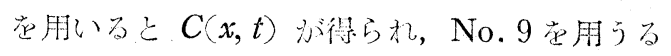
と拨散電流值 $i(\hat{b})$ 办得方れる4).

\section{〔問題 3】}

…良電流密度 $i_{0}=i / q$ を用いて䉓解を行う際 の $C(x, t)$ 在求》上。文は Chronopotentiometry の基儊理論を形成するもので，競界条作 㳉,

$$
t>0, x=0, D_{0} \frac{\partial C_{0}}{\partial x}=-D_{\mathrm{R}} \frac{\partial C_{\mathrm{R}}}{\partial x}=\frac{i_{0}}{n \mathrm{~F}}
$$

によ一て六される。奖撸衣 No.12 並に出中及

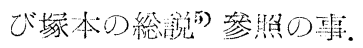

\section{文献}

1) J. Koutecky and R. Brdicka, Gollection 12 (1947) 337.

2) A. Sevcik, Collection 13 (1948) 349 .

3) S. Glasstone, "Elements of Physical Chemistry" (1946) p. 208. 
4) P. Delahay, "New Instrumental Methods in Electrochemistry". (1954) p. 72

5) 由1中：化学の領域，9(1955) 638, 塚本 : 水一ロダラフィー, 4 (1956) 3.

ラプラス変換についての成書の数例以次に龍す 通りである。

6) R. V. Churchill, "Modern Operational Mathematics in Engineering." (1944) McGraw-Hill. Book Co.

7) R. V. Churchill 著：洪四方次訳「応用ラプラス 変換」(炤25年) 彰国社.

8) K. W. Wagner, "Operatorenrechnung nebst Anwendungen in Physik und Technik" (1940).

9) K. W. Wanger 著, 太原彦一訳 : 「演算子法解説」 (昭18) 科学新與社.

10) K. W. Wagner, "Operatorenrechnung und Lap- lacesche Transformation. 2. Auflage (1950) Johann Ambrosius Barth, Leipzig.

11) N. W. McLachlan et P. Humbert, "Formulaire pour le calcul symbolique" (1941) GauthierVillars, Paris.

12) 林重憲: 「過渡現象の数学似方沙一初等原叫符」 (膘17) 健文社.

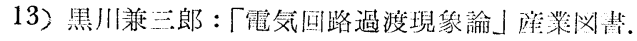

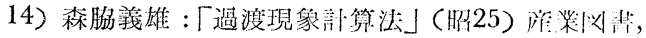

15) 林重憲：「演算子法解説」霍父青院。

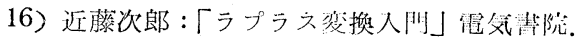

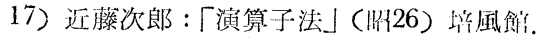

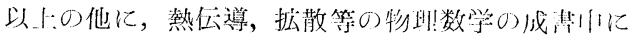

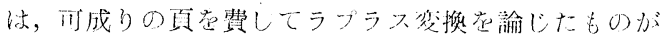
多い。

[1956-2-6 㴗叫! $]$

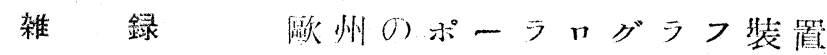

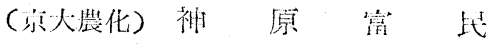

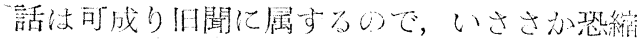
の次第であるが，1955作５月に独の Frankfurt am Main で閉かれた ACHEMA の見本

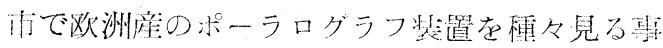

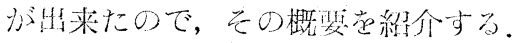

ACHEMA \& Ausstellungs-Tagung für chemisches Apparatwesen ひ略称で, その䍬細 は涞原和作氏の旅行記〔化学上土業, 3(1956) 3〜8〕に詳しく述べられて佸るので，ここでは

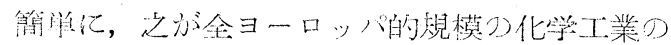
見本书であると要約して, 長談䉝在省略しよ う。此所に出品されたボーラログラフ装置の製 造業者在列記すると次のようである。

(1) Atlas-Werke AG, Bremen

(2) Metrohm AG, Herisau

(3) Hartmann \&. Braun AG, Frankfurt a. M.
(4) Dr. B. Lange, Berlin

(5) Dr. A. Kuntze, Düsseldorf

(6) Joberg Ltd., London

(7) LKB Produkter, Stockholm

(8) Radiometer, K$\phi$ benhavn

(9) Dr. Virus, Bonn

(10) E. Leybold's Nachfolger, Köln

一般に欧洲の装檤は雷于管自動可衡广式のも のが発売されて居らず，霓流值を直流增㠷て 記録計に入れるものが多い。(10)の装㥜の製作

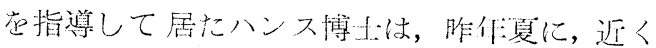

Kompensograph を用いた装置を作る計画だし

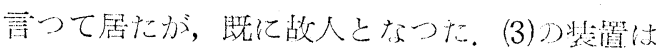
Antweiler, Collection 15 (1950) 717 飞報等 されたもの存商品化したものである。炏洲の济

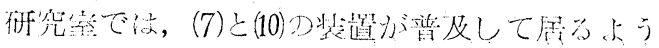
に思われる。 